\title{
UNA ESPADA DE ÉPOCA OMEYA DEL SIGLO IX D. C.
}

POR

\author{
ALBERTO CANTO GARCÍA
}

\section{RESUMEN - ABSTRACT}

Se da a conocer un importante hallazgo de época emiral, compuesto por una espada y un conjunto de dirhem ocultados hacia el año 880 d. C. Esta cronología supone que se trata de la Espada más antigua conocida hasta el momento procedente de al-Andalus.

This article presents an important finding from al-Andalus emirate, composed of a sword and a group of dirhem hiding circa 880 a. C. This chronology implies it is the eldest sword known from al-Andalus.

\section{PALABRAS CLAVE - KEY WORDS}

Armas blancas. Espada. Al-Andalus. Emirato. Omeyas. Numismática.

White arms. Sword. Al-Andalus. Umayyad Emirate. Numismatics.

En una colección privada española se conserva un conjunto compuesto por una espada, la contera de la funda y un grupo de monedas (Fig. 1) cuya proveniencia se atribuye a la provincia de Córdoba, hecho este, que no se puede asegurar con total certeza.

Lo más importante de este material es el hecho de que la citada espada apareciese junto con un lote de monedas omeyas de plata, dirhemes, del emirato Omeya de al-Andalus, con capital en Córdoba. Si aceptamos que las monedas y la espada provienen de un mismo depósito nos encontraríamos ante la primera arma de este tipo fechada con cierta exactitud.

De forma clara la espada y la contera deben formar parte de un conjunto que incluía la vaina de la misma que, con toda posibilidad, debía estar compuesta por cuero u otro material que se ha perdido con el paso del tiempo; de hecho dentro de la contera metálica se aprecian restos de fibras del citado componente.

La espada, en cuestión, se conserva en una pieza (Fig. 2), aunque en la espiga del mango ha sufrido una restauración posterior en la que se añadió un elemento central moderno en su parte central, posiblemente para enlazar con el pomo de la misma que debió aparecer rota o se partió en un momento posterior (Fig. 3). Se puede apreciar en la foto que el pomo rematado en forma de $\mathrm{T}$ conserva parte del arranque de la espiga que, a su vez, hecho el añadido enlaza con la cruz del mango .

Se trata de una espada larga recta, de hoja de doble filo, de hierro forjado (a falta de metalografías y estudio radiológico que permitan comprobar su estructura interna) con una hoja de una longitud de $79 \mathrm{cms}$, unido a un arriaz rectangular que da paso al puño. Éste, como hemos indicado, no se conserva en su totalidad, ya que del original sólo restan los extremos. 


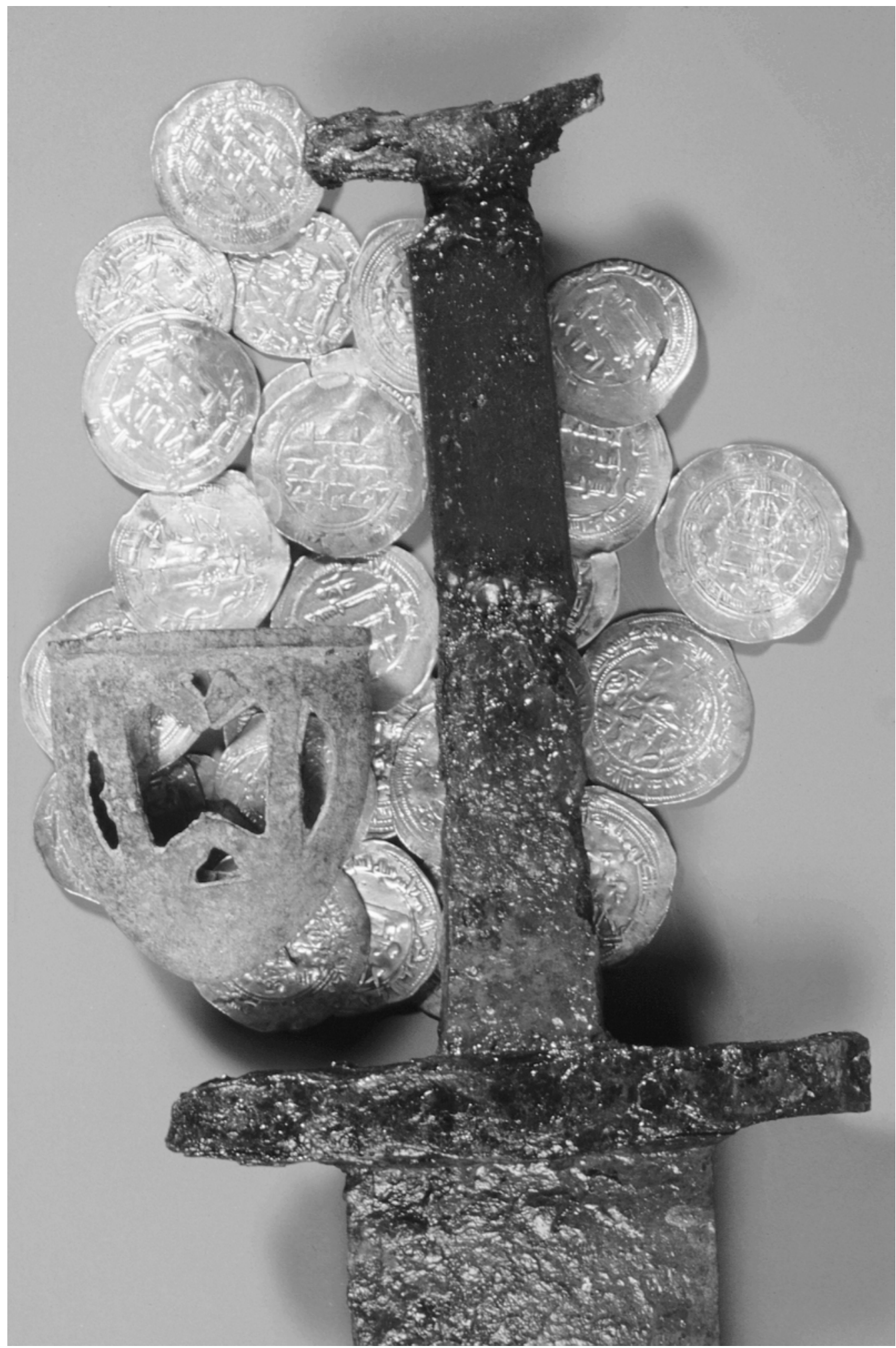

Fig. 1.- Conjunto de espada, contera y monedas. 


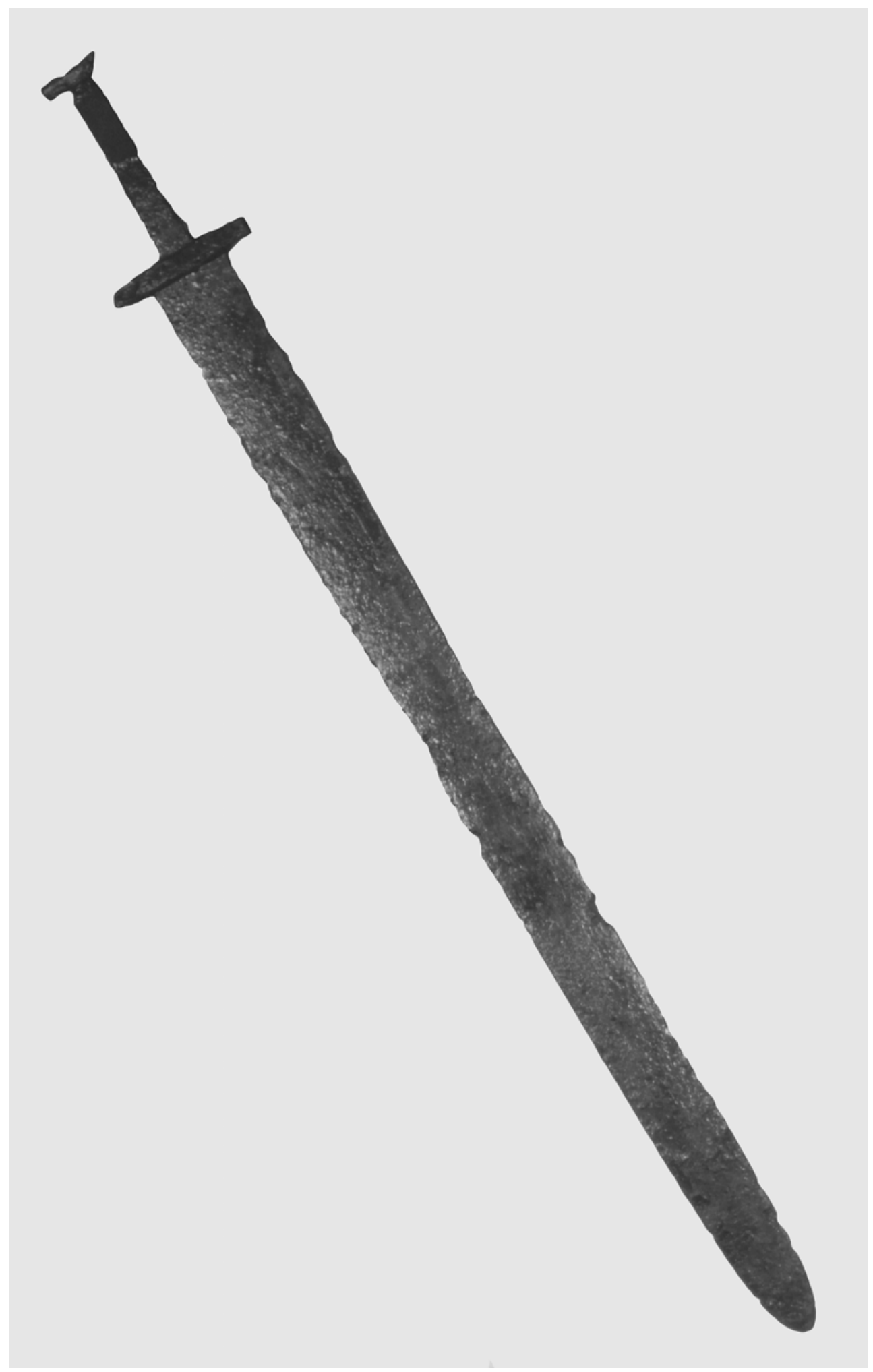

Fig. 2.- Espada. 


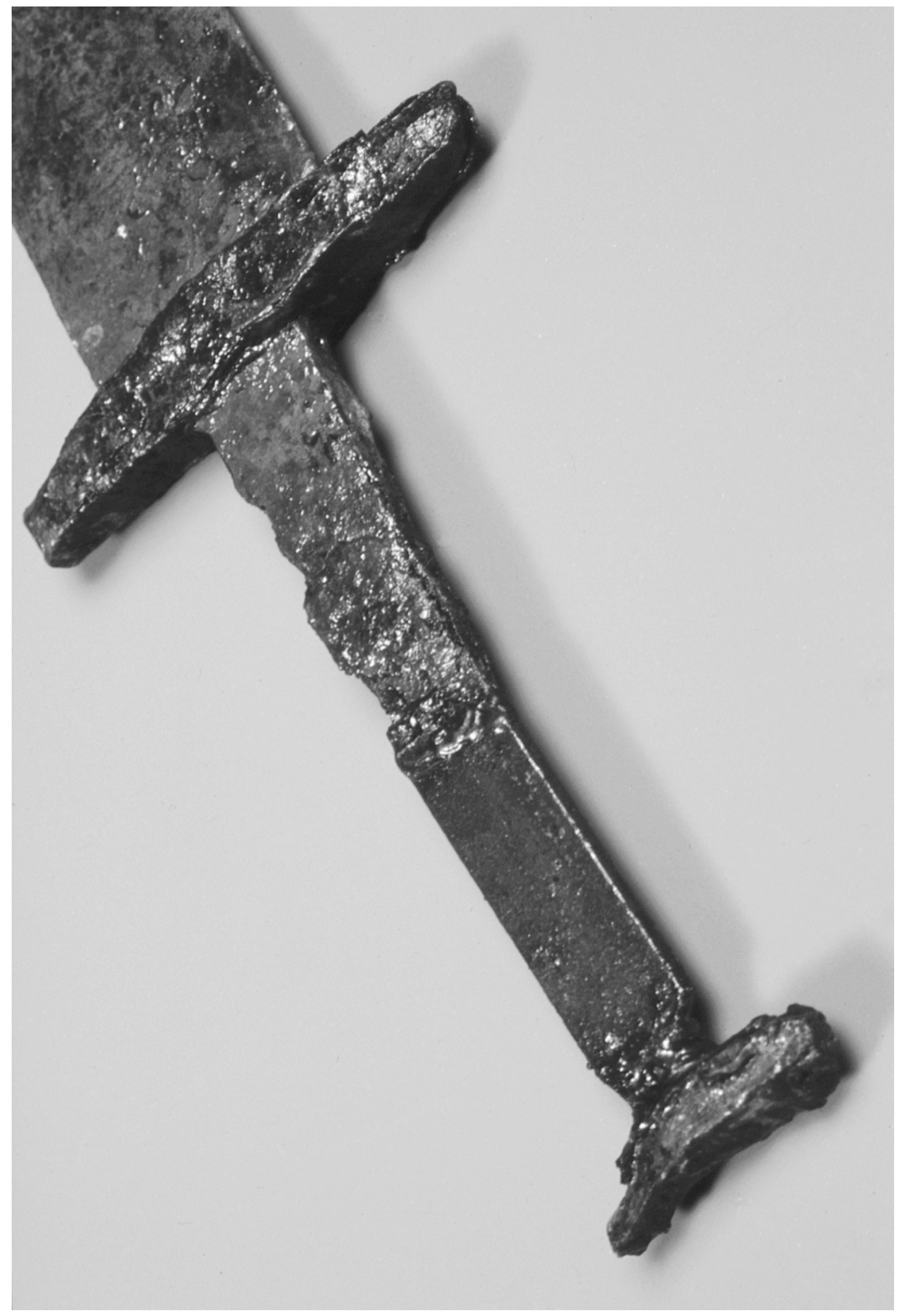

Fig. 3.- Detalle de la empuñadura de la espada con el añadido moderno. 
Desde el arriaz hasta el pomo mide $12,5 \mathrm{cms}$ con una sección rectangular; en este caso y ante la presencia del añadido posterior, ya mencionado, y que se identifica con claridad, la medida proporcionada debe ser considerada con precaución al no poder determinar la longitud exacta del puño.

La hoja tiene un ancho de $55 \mathrm{~mm}$. en su conexión con el arriaz, y se va estrechando, de forma paulatina, hasta el final; este estrechamiento hacía la punta sólo se acentúa en los últimos cinco centímetros del final.

La contera es una pieza de bronce, calada, con una pátina verdosa obscura (Figs. 4 y 5). Aunque ligeramente deformada tiene unas medidas de $51 \mathrm{~mm}$. de alto por 48 de ancho, con un pequeño reborde o labio de $3 \mathrm{~mm}$. en su parte superior. Las medidas interiores son, en sentido longitudinal de $43 \mathrm{~mm}$, por $13 \mathrm{~mm}$. en su zona estrecha. Permite, sin ningún problema, la introducción de la hoja y la funda de material perecedero que la acompañara en su momento.

Ambas caras están caladas con unos dibujos semejantes compuestos por un cuadrado cuyos lados superior e inferior tienen forma de pirámide invertida; están superados por un pequeño triángulo en cada cara. Lo flanquean dos segmentos de círculo.

En ninguna de las piezas mencionadas se han encontrado restos de epigrafía o letras aisladas.

La atribución de esta espada es un tema de bastante dificultad ante la carencia de paralelos fiables. De entre los escasos citados algunos de los que presentan mayores similitudes están atribuidos a fecha posterior; así ocurre con alguna de las espadas citadas por D. Nico$1 e^{1}$. La referencia número 382 es bastante diferente siendo más semejante, en lo referente a la empuñadura, la número 388 por el travesaño central de la empuñadura, parecido en sección a la espada que aquí se presenta pero de menor longitud.

Los materiales hallados con un relativo contexto arqueológico también son de una fecha algo posterior como ocurre con el ejemplar hallado en el pecio de Agay, atribuído al siglo X, que por su tamaño se asemeja algo al ejemplar aquí estudiado ${ }^{2}$.

De igual forma ocurre con la espada presentada en el conjunto de Lietor cuyos límites cronológicos oscilan entre el siglo X-XI; en este caso las diferencias formales son más grandes, puesto que la espada de Lietor es, sensiblemente, más corta . Además presenta alguna diferencia de importancia en la forma de realizar la empuñadura que en el caso de Lietor es una espiga terminada en punta indicada para enmangar y sin travesaño horizontal, mientras que el ejemplar que analizamos tiene una solución diferente con la presencia del pomo y una espiga que sugiere una empuñadura que debe fabricarse de forma distinta ${ }^{3}$.

Resulta imposible afirmar, a tenor de los datos disponibles, el origen ni el lugar de fabricación de esta arma pero considero que, por el contrario, si se puede precisar con mucha exactitud el momento de su uso y ocultación, se debiera a los motivos que fueran.

\footnotetext{
1 En D. Nicolle (1999), Arms \& Armour of the Crusading Era 1050-1350. Islam, Eastern Europe and Asia, Londres.

2 D. Brentchaloff y Ph. Senac, (1991), «Note sur l'epave sarrasine de la rade d'Agay (Saint-Raphaël, Var)», Archéologique islamique, 2, p. 77, fig. 6.

3 J. Navarro Palazón y A. Robles Fernández (1996), Lietor. Formas de vida rurales en Sarq al-Andalus a través de una ocultación de los siglos X-XI, Serie Islam y Arqueología 2, Murcia, p. 93, nº 147.
} 

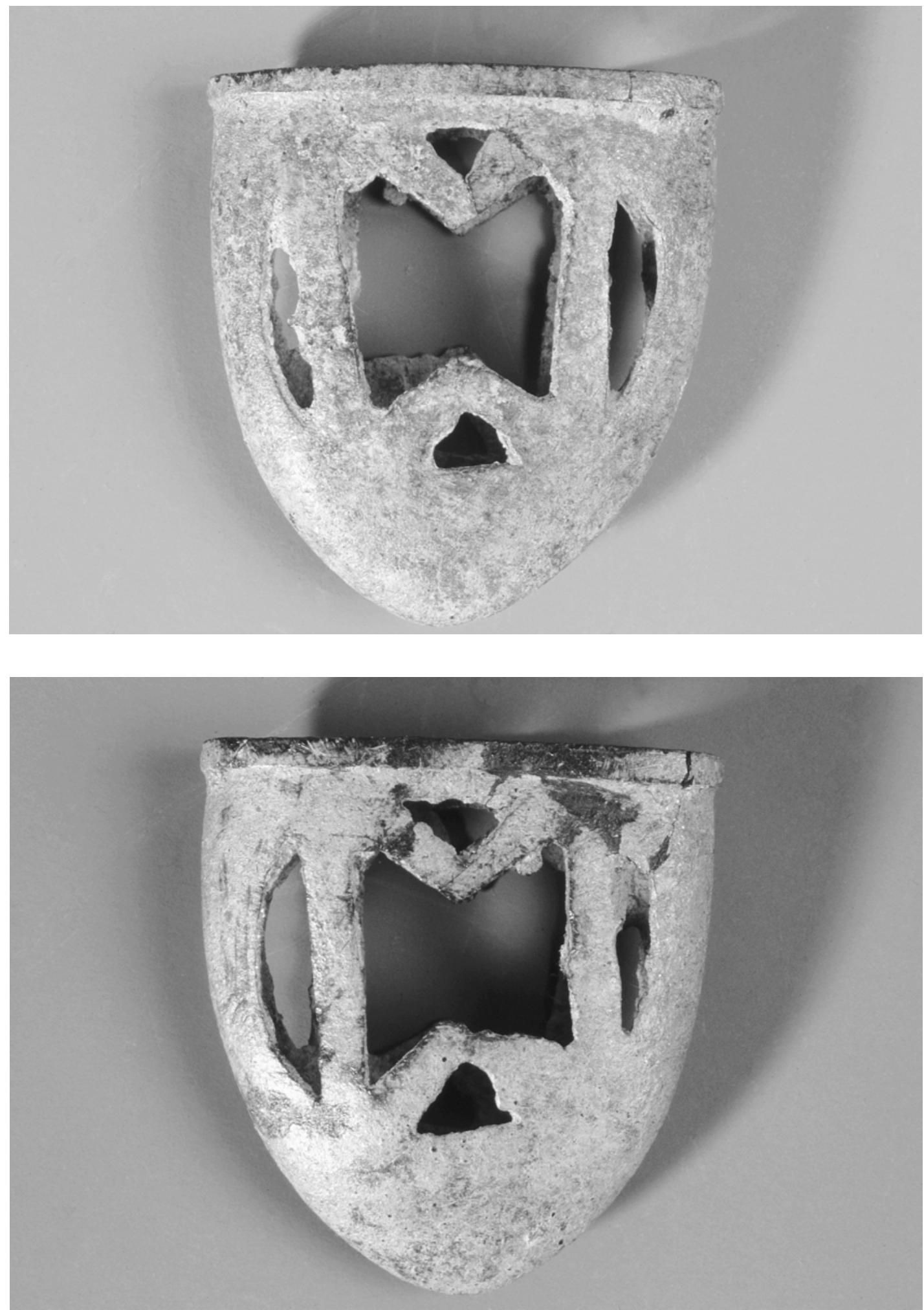

Figs. 4-5.- Contera vista por ambos lados. 


\section{CONJUNTO DE MONEDAS ${ }^{4}$}

Todas las piezas son dirhemes del emirato Omeya, de la ceca de al-Andalus (Fig. 6) y no existe ninguna información disponible sobre la forma en que aparecieron acompañando a la espada; es decir si estaban en una cerámica (el contenedor habitual para los ocultamientos de monedas), bolsa u otro recipiente de cualquier especie.

Las piezas números 21 a 27 presentan problemas de lectura en sus fechas, que no pueden ser determinadas con exactitud; sin embargo por aspecto, estilo y los restos de los dígitos corresponden, todas ellas, a ejemplares de las décadas entre el 220 y el $240 \mathrm{H}$. Por lo tanto son coherentes con el resto del material numismático y no suponen ninguna alteración a la datación propuesta para el ocultamiento.

Como puede apreciarse todas las monedas conservadas, incluso las de lectura incierta, se adscriben a las emisiones de los emires omeyas de Córdoba. No existe ningún ejemplar de otra dinastía norteafricana u oriental, así como tampoco ninguna moneda o fragmento de la misma procedente de Europa Occidental.

Todas ellas se distribuyen entre los tres emires Al-Hakam I, 'Abd al-Raḥmān II y Muhammad I, no habiendo ninguna pieza posterior que se pueda atribuir a cualquiera de sus sucesores. Por ello la cronología del conjunto de monedas no puede exceder, en demasía, la fecha de la última moneda leída, la no 20 del año 264H./ 877-8 d.C.

No es este el lugar de analizar la evolución del sistema monetario omeya en esta época pero la sistemática de los hallazgos realizados en más de un siglo de investigación numismática han determinado, con bastante exactitud, los márgenes de circulación de este tipo de moneda y su desaparición de la circulación en momentos determinados. La ausencia de ejemplares pertenecientes al reinado de al-Mundir o 'Abd Allāh, los dos últimos emires de Al-Andalus del denominado Emirato Independiente de al-Andalus antes de la aparición de 'Abd al-Rạ̣mān III, ratifican que el momento de ocultación de estas monedas debió ser anterior a los años 70 del siglo III H./IX d. C.

Algo que puede resaltarse en este lote de monedas en la estrecha banda cronológica en la que se enmarcan los ejemplares aparecidos unos 62 años; sabemos que la mayoría de los hallazgos de esta época suelen incluir ejemplares de los emires del siglo VIII, tanto 'Abd al-Raḥmān I como Hišām I, de quienes no hay ningún ejemplar en este hallazgo. Por ello se puede presumir que no se trata de un conjunto de monedas atesorado durante un espacio de tiempo muy largo sino realizado de una forma más selectiva y centrado en los años de Muhammad I. No hay que olvidar que los ejemplares fechados de Al-Ḥakam I son sólo tres piezas y las de `Abd al-Rạ̣mān II, cinco, aunque cabe la posibilidad de alguna más dentro de las piezas dudosas.

La ausencia de materiales numismáticos califales realza esta suposición cronológica aunque la convivencia de la moneda emiral y la califal, en las ocultaciones, es algo extraordinario.

Convendría, desde el punto de vista monetario, realizar otras dos precisiones: por un lado la ausencia de monedas fragmentadas, tan frecuentes en los hallazgos de época omeya, aunque como se indica en el catálogo algunas de las monedas presentan las alteraciones clásicas para monedas de esta época, hendiduras y recortes de las orlas ${ }^{5}$ y la ausencia de cualquier moneda de cobre (felús).

4 En el listado se han dispuesto los ejemplares por orden cronológico, seguido de su peso (en gramos), el módulo (en milímetros) y la referencia de Vives (Antonio Vives Escudero, Monedas de las dinastías Arábigo-españolas, Madrid 1893). Las letras R o H que aparecen detrás de los datos físicos indican si las monedas están recortadas o presentan hendiduras en su campo, factores estos que alteran sus valores metrológicos. La marca XXX indican monedas cuya fecha es ilegible por el estado de conservación de la moneda.

5 Sobre este aspecto Canto García, A./Marsal Moyano, E., (1988), «Hallazgo emiral de Iznajar (Granada), AlQantara 9, pp. 427-70 y Ibrahim, T./Canto, A. (1991)», Hallazgo emiral en Puebla de Cazalla (Sevilla), Numisma 229, pp. 69-86. 


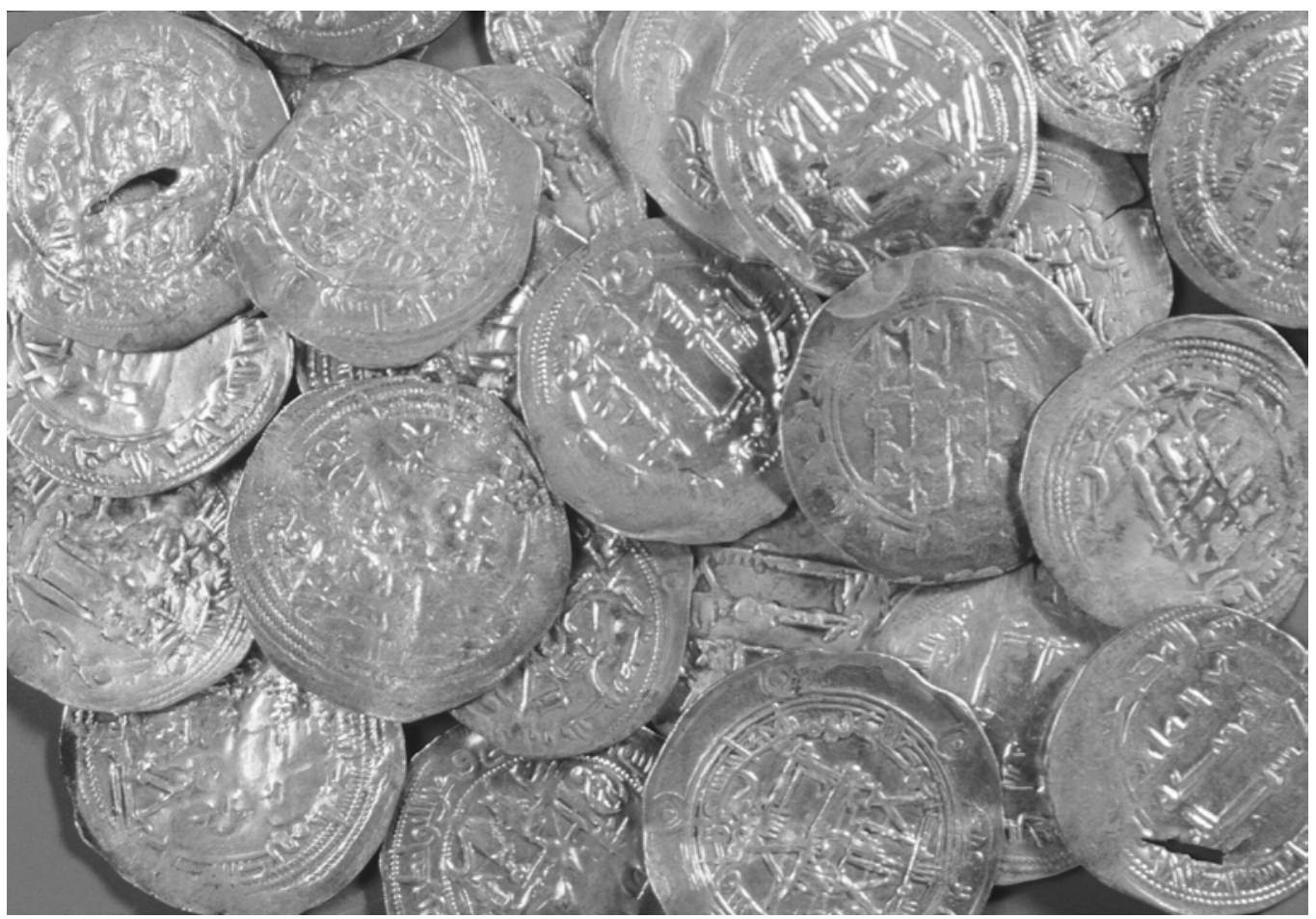

Fig. 6.- Conjunto de monedas.

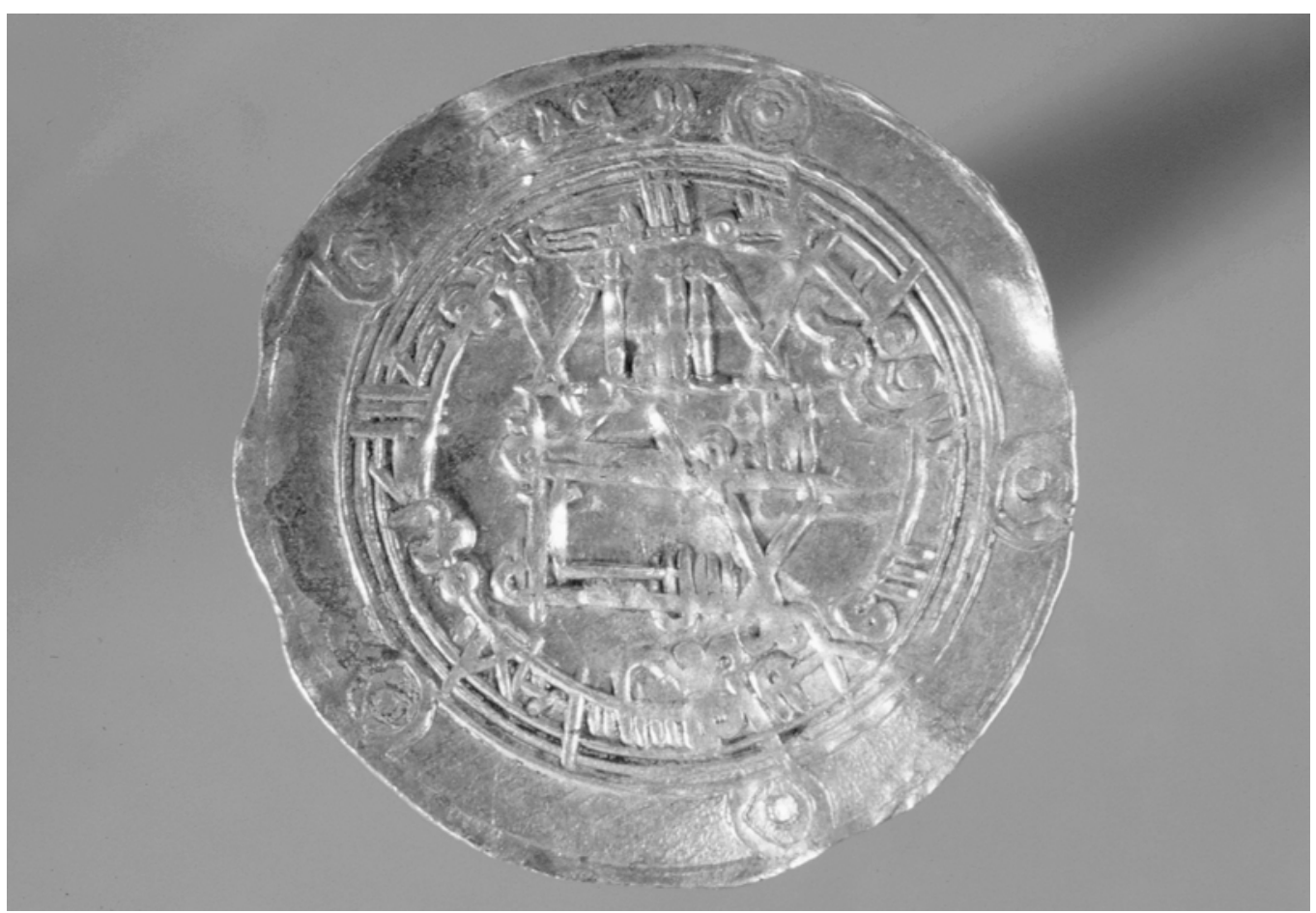

Fig. 7.- Dirhem del año 264H./877-78 d. C. 
Resulta imposible, a la vista de la información disponible realizar cualquier interpretación sobre el conjunto, excepto la propuesta de determinación de la fecha de ocultación del mismo; la presencia de algunos restos de anillos parece sugerir que todo el material formaba parte de las pertenencias de un individuo; la ausencia mencionada de fragmentos de monedas hace más creíble la interpretación de una bolsa de viaje o monedas portadas por el propietario, que no el de la clásica acumulación de monedas y fragmentos que definen los ocultamientos emirales.

\section{CATÁlogo}

Al-Hạkam I (180-206H./796-822 d. C.)

$\begin{array}{llllll}1 .- & 202 / 817-8 & 2,58 & 27 & & \text { Vives } 114 \\ \text { 2.- } & 203 / 818-9 & 2,54 & 27 & & \text { Vives } 116 \\ \text { 3.- } & 206 / 821-2 & 2,02 & 23 & \text { R } & \text { Vives } 120\end{array}$

'Abd al-Rạ̣mān II (206-238H./822-852 d. C.)

$\begin{array}{llllll}\text { 4.- } & 222 / 836-7 & 2,12 & 23 & & \text { Vives 164 } \\ \text { 5.- } & 231 / 845-6 & 2,64 & 27 & & \text { Vives 198 } \\ \text { 6.- } & 234 / 848-9 & 2,54 & 30 & & \text { Vives 205 } \\ \text { 7.- } & 235 / 849-50 & 2,60 & 26 & \text { H } & \text { Vives 208 } \\ \text { 8.- } & 238 / 852-3 & 1,50 & 24 & \text { R,H } & \text { Vives 223 }\end{array}$

Muhammad I (238-273H./852-886 d. C.)

$\begin{array}{llllll}\text { 9.- } & 240 / 854-5 & 2,48 & 26 & & \text { Vives 235 } \\ \text { 10.- } & 242 / 856-7 & 2,34 & 25 & \mathrm{H} & \text { Vives 243 } \\ \text { 11.- } & 246 / 860-1 & 2,58 & 26 & & \text { Vives 254 } \\ \text { 12.- } & 248 / 862-3 & 2,48 & 26 & & \text { Vives 256 } \\ \text { 13.- } & 249 / 863-4 & 2,30 & 27 & & \text { Vives 257 } \\ \text { 14.- } & 250 / 864-5 & 2,52 & 26 & & \text { Vives 258 } \\ \text { 15.- } & 250 / 864-5 & 2,06 & 24 & \mathrm{R} & \text { Vives 260 } \\ \text { 16.- } & 250 / 864-5 & 2,46 & 27 & \mathrm{H} & \text { Vives 258 } \\ \text { 17.- } & 251 / 865 & 2,50 & 28 & & \text { Vives 262 } \\ \text { 18.- } & 252 / 866 & 2,64 & 28 & & \text { Vives 244 } \\ \text { 19.- } & 255 / 868-9 & 2,56 & 29 & & \text { Vives 271 } \\ \text { 20.- } & 264 / 877-78 & 2,52 & 29 & & \text { Vives 295 } \\ \text { 21.- } & \text { XXX } & 2,40 & 26 & & \\ \text { 22.- } & \text { XXX } & 2,54 & 25 & & \\ \text { 23.- } & \text { XXX } & 2,50 & 27 & & \\ \text { 24.- } & \text { XXX } & 1,64 & 24 & & \\ \text { 25.- } & \text { XXX } & 2,38 & 27 & & \\ \text { 26.- } & \text { XXX } & 2,58 & 27 & & \end{array}$

\footnotetext{
Alberto CANTO GARCÍA

Departamento de Prehistoria y Arqueología, Universidad Autónoma de Madrid.

e-mail:alberto.canto@uam.es
} 